OBSERVATIONS TENDRIL FINGERS PATTERN AND PALMS IN CHILDREN WITH ADHD (ATTENTION DEFICIT HYPERACTIVITY DISORDER) IN PADANG CITY

\title{
PENGAMATAN POLA SULUR JARI DAN TELAPAK TANGAN PADA ANAK PENYANDANG ADHD (ATTENTION DEFICIT HYPERACTIVITY DISORDER) DI KOTA PADANG
}

\section{Meliya Wati*, Ruth Rize Paas Megahati, Fitri Hayuni}

Program Studi Pendidikan Biologi STKIP PGRI Sumatera Barat.

Jl. Gunung Pangilun, Kota Padang, Sumatera Barat, Indonesia.

Telp./Fax.(0751)7053731/(0751)7053826. Email:meliyawatibio0310@gmail.com. Manuskript diterima: 20 Mei 2016. Revisi disetujui: 24 Juni 2016

\begin{abstract}
Fingerprint patterns vary, and the pattern is not the same from one individual to another individual. During its development, the patterns tendrils widely used for identity, the latest technology the pattern of tendrils or known by fingerprint applied to e-cards, as a forensic tool for police forces and until now growing research that examines relationships patterns of typical fingerprint with diseases that are genetic. Today many common hereditary disease associated with hyperkinetic disorders, attention deficit hyperactivity disorder (ADHD), or approximately $80 \%$ of the difference between children who have symptoms of $A D H D$ in society will be determined by genetic factors. This study aims to determine the patterns of fingerprints and palms in children with ADHD and compared with normal children. The method used is descriptive method. The results showed children with ADHD have a type plain whorl $34.5 \%$, more than the normal children (16\%) and based on the statistics, there is a noticeable difference. The average number of vines fingertips with ADHD was higher than normal children (146.3> 136.5). Observations pattern on the palms showed interdigital 4 had the highest frequency (50\%) and there is no real difference between ADHD children with normal children.
\end{abstract}

Keyword: fingerprint types, attention deficit hyperactivity disorder(ADHD), genetics

\section{ABSTRAK}

Pola-pola sidik jari bermacam-macam, dan pola tersebut tidak sama antara satu individu dengan individu lain. Dalam perkembangannya, pola-pola sulur banyak dimanfaatkan untuk identitas, teknologi terbaru pola sulur atau yang dikenal dengan sidik jari diaplikasikan untuk $e$-card, sebagai alat forensik bagi kepolisian dan hingga saat ini berkembang penelitian yang mengkaji hubunganhubungan pola-pola khas sidik jari dengan penyakit-penyakit yang sifatnya 
genetik. Dewasa ini banyak dijumpai penyakit keturunan yang berhubungan dengan gangguan hiperkinetik, attention deficit hyperactivity disorder (ADHD) atau sekitar $80 \%$ dari perbedaan antara anak-anak yang mempunyai gejala ADHD dalam kehidupan bermasyarakat akan ditentukan oleh faktor genetik. Penelitian ini bertujuan untuk mengetahui pola-pola sidik jari dan telapak tangan pada anakanak penyandang ADHD dan dibandingkan dengan anak yang normal. Metode yang digunakan adalah metode deskriptif. Hasil penelitian menunjukkan pada anak-anak penyandang ADHD memiliki tipe plain whorl 34,5\%, lebih banyak dibandingkan dengan anak normal (16\%) dan berdasarkan statistik, terdapat perbedaan yang nyata. Rata-rata jumlah sulur ujung jari tangan penyandang ADHD lebih tinggi dibandingkan dengan anak normal (146,3>136,5). Pengamatan pola pada telapak tangan menunjukkan pada interdigital 4 memiliki frekuensi tertinggi $(50 \%)$ dan terdapat perbedaan yang tidak nyata antara anak penyadang ADHD dengan anak normal.

Kata kunci: tipe pola sidik jari, ADHD, genetika

\section{PENDAHULUAN}

Dermatoglifi merupakan ilmu yang mempelajari sulur pada ujung jari tangan, telapak tangan, telapak kaki, dan jari-jari kaki (Abilasha, Harisudha dan Janaki, 2014). Pola dermatoglifi terbentuk sejak awal perkembangan embrio mulai dari embrio berumur 13 sampai 24 minggu kehamilan. Pembentukan dermatoglifi ini bersifat poligen yaitu dipengaruhi oleh banyak gen (Misbach, 2010).

Pola-pola sidik jari bermacam-macam, dan pola tersebut tidak sama antara satu individu dengan individu lain. Pola sidik jari secara garis besar terdiri dari tiga tipe, yaitu tipe arch, loop dan whorl (Rafiah, dkk., 1998). Dalam perkembangannya, pola-pola sulur banyak dimanfaatkan untuk identitas, teknologi terbaru pola sulur atau yang dikenal dengan sidik jari diaplikasikan untuk e-card, sebagai alat forensik bagi kepolisian dan hingga saat ini berkembang penelitian yang mengkaji hubungan-hubungan pola-pola khas sidik jari dengan penyakit-penyakit yang sifatnya genetik.

Penelitian Sudarmi, (2004) dimana pada daerah interdigital III frekuensi pola lebih rendah dibandingkan dengan anak-anak normotensi, sedangkan pada daerah lainnya menunjukkan frekuensi yang hampir setara, penelitian Putriani (2006) adanya karakteristik tertentu pada pola sulur pada telapak tangan anak autisme, dimana tidak ditemukan pola sulur telapak tangan pada daerah interdigital $\mathrm{I}_{1}, \mathrm{I}_{2}, \mathrm{I}_{3}$, dan Thenar. 
Sufitni (2007) juga meneliti tentang pola sidik jari pada penderita retardasi mental dan memperoleh kesimpulan bahwa sekelompok retardasi mental memiliki pola arch lebih banyak dan jumlah rigi sidik jarinya lebih rendah dibandingkan kelompok normal. Terutama bagi penderita penyakit genetik biasa memiliki jumlah rigi sidik jari yang lebih rendah dibandingkan dengan kelompok normal.

Sufitni ( 2007 ) mengemukakan bahwa penyakit yang dapat dihubungkan dengan dermatoglifi seperti: Alzheimer, tuberculosis, diabetes, kanker dan penyakit jantung. Penulis juga berpendapat bahwa selain penyakit-penyakit di atas masih ada penyakit hereditas lain yang dapat dihubungkan dengan dermatoglifi diantaranya attention deficit hyperactivity disorder (ADHD) atau gangguan pemusatan perhatian disertai hiperaktif. Menurut Paternotte (2010), salah satu penyebab ADHD adalah faktor keturunan dan berperanan sekitar $80 \%$.

\section{BAHAN DAN METODE}

\section{Rancangan Penelitian}

Penelitian ini dilakukan dengan metode purposive sampling untuk anakanak penyandang ADHD dan random sampling untuk anak-anak normal. Kriteria khusus pada anak-anak penyandang ADHD yang dapat dijadikan responden adalah tidak adanya kelainan yang ditemukan pada permukaan jari dan telapak tangan.

\section{Alat dan Bahan}

Dalam penelitian ini alat yang digunakan diantaranya adalah busur derajat, kartu rekaman sidik jari, lempeng kaca, lup, lap kain, tisu dan penggaris, sedangkan bahan yang digunakan adalah sidik penderita tuna grahita dan normal, tinta stensil dan sabun.

\section{Prosedur Penelitian}

Sebelum melakukan penelitian, perlu dilakukan observasi ke SLB yang mendidik anak-anak penyandang ADHD dan mempersiapkan perizinannya. Pelaksanaan penelitian dilakukan di SLB kota Padang. Rekam sidik jari diambil dengan menggunakan tinta stempel dan disalin pada HVS. Kemudian dihitung tipe-tipe pola sulur dan menghitung frekuensi pola sulur. Hasil rekam sidik jari 
anak-anak ADHD dibandingkan dengan anak-anak yang normal (tidak menderita tuna grahita).

\section{Analisis Data}

Data dianalisis dengan statistik (chi-square) tipe pola pada jari tangan dan telapak tangan anak-anak ADHD dengan anak normal.

\section{HASIL}

\section{Tipe Sulur pada Ujung Jari Tangan}

Hasil pengamatan terhadap frekuensi tipe pola sulur ujung jari tangan anak-anak penyandang ADHD dan normal dapat dilihat pada Gambar 1.

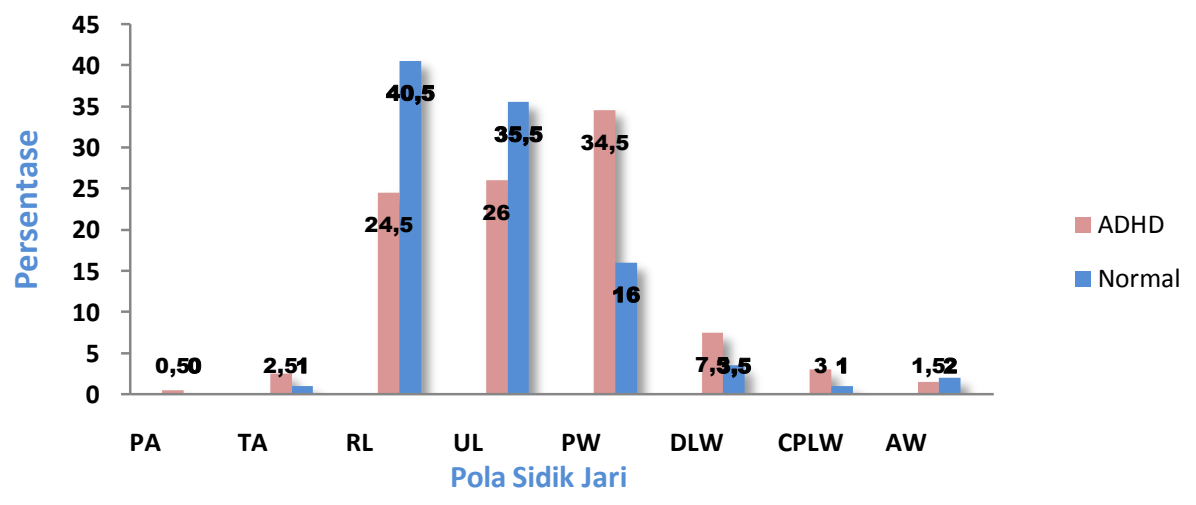

Gambar 1. Gambaran perbandingan dan sebaran pola sidik jari pada anak-anak pengandang ADHD dan anak-anak normal. Keterangan: $P A=$ plain arch, $P W=$ plain whorl, $T A=$ tanted arch, $D L W=$ double loop whorl, $R L=$ radial loop, $C P L W=$ central plain loop whorl, $U L=$ ulnar loop, $A W=$ accidental whorl.

Pada Gambar 1 dapat dilihat bahwa persentase tertinggi pada anak-anak penyandang ADHD terdapat pada tipe plain whorl dan tipe terendah adalah tipe plain arch. Pada anak-anak normal tipe tertinggi adalah tipe radial loop dan terendah plain arch. Berdasarkan uji statistik (chi square) antara tipe-tipe pola sidik jari pada dua kelompok tersebut berbeda nyata, dengan nilai $\mathrm{X}^{2} \mathrm{~h}=31,7$ dan $X^{2} t=14,06$.

Untuk lebih jelasnya sebaran tipe-tipe pola sidik jari tersebut dapat dilihat pada Tabel 1 berikut: 
Tabel 1. Frekuensi dan Persentase Tipe Pola Sulur Ujung Jari Tangan Anak-Anak ADHD dan Anak-Anak Normal

\begin{tabular}{|c|c|c|c|c|c|c|c|c|c|c|c|c|c|c|c|c|c|}
\hline \multirow{3}{*}{ KLP } & \multirow{3}{*}{$\mathbf{N}$} & \multicolumn{16}{|c|}{ Tipe } \\
\hline & & \multicolumn{2}{|c|}{ PA } & \multicolumn{2}{|c|}{ TA } & \multicolumn{2}{|c|}{ RL } & \multicolumn{2}{|c|}{ UL } & \multicolumn{2}{|c|}{ PW } & \multicolumn{2}{|c|}{ DLW } & \multicolumn{2}{|c|}{ CPLW } & \multicolumn{2}{|c|}{ AW } \\
\hline & & $\mathbf{N}$ & $\%$ & $\mathbf{N}$ & $\%$ & $\mathbf{N}$ & $\%$ & $\mathbf{N}$ & $\%$ & $\mathbf{N}$ & $\%$ & $\mathbf{N}$ & $\%$ & $\mathbf{N}$ & $\%$ & $\mathbf{N}$ & $\%$ \\
\hline ADHD & 20 & 1 & 0,5 & 5 & 2,5 & 49 & 24,5 & 52 & 26 & 69 & 34,5 & 15 & 7,5 & 6 & 3 & 3 & 1,5 \\
\hline Normal & 20 & 0 & 0 & 2 & 1 & 81 & 40,5 & 71 & 35,5 & 32 & 16 & 7 & 3,5 & 2 & 1 & 4 & 2 \\
\hline
\end{tabular}

Pada Tabel 1 dapat dilihat bahwa persentase pola tertinggi adalah plain whorl pada anak-anak penyandang ADHD (34,5\%) sedangkan pada anak normal yang tertinggi adalah radial loop $(40,5 \%)$.

\section{Frekuensi Pola Sulur Telapak Tangan}

Pengamatan pola sulur telapak tangan anak-anak penyandang ADHD dan normal dapat dilihat pada Tabel 2 .

Tabel 2. Frekuensi dan Persentase Pola Sulur Telapak Tangan Anak-Anak ADHD dan Anak Normal

\begin{tabular}{|c|c|c|c|c|c|c|c|c|c|c|c|c|c|}
\hline \multirow{3}{*}{ Kelompok } & \multirow{3}{*}{$\mathbf{N}$} & \multicolumn{12}{|c|}{ Daerah Telapak Tangan } \\
\hline & & \multicolumn{2}{|c|}{ Th } & \multicolumn{2}{|c|}{$\mathbf{H}$} & \multicolumn{2}{|c|}{$\mathbf{I}_{1}$} & \multicolumn{2}{|c|}{$I_{2}$} & \multicolumn{2}{|c|}{$\mathbf{I}_{3}$} & \multicolumn{2}{|c|}{$\mathbf{I}_{4}$} \\
\hline & & $\mathbf{N}$ & $\%$ & $\mathbf{N}$ & $\%$ & $\mathbf{N}$ & $\%$ & $\mathbf{N}$ & $\%$ & $\mathbf{N}$ & $\%$ & $\mathbf{N}$ & $\%$ \\
\hline ADHD & 20 & 2 & 5 & 3 & 7,5 & 1 & 2,5 & 0 & 0 & 18 & 45 & 20 & 50 \\
\hline Normal & 20 & 0 & 0 & 1 & 2,5 & 0 & 0 & 0 & 0 & 17 & 42,5 & 21 & 50,25 \\
\hline
\end{tabular}

Pada Tabel 2 dapat dilihat bahwa frekuensi dan persentase pola sulur pada anak-anak ADHD yang tertinggi adalah pada Interdigital III yaitu 18 dan $45 \%$, dan yang terendah adalah Interdigital I yaitu 1 dan 2,5\%. Pada anak-anak yang tidak menderita ADHD yang tertinggi Interdigital IV yaitu 21 dan 50,25 \% dan terendah Interdigital dan thenar yaitu 0 .

\section{PEMBAHASAN}

\section{Tipe Sulur pada Ujung Jari Tangan}

Tipe pola yang ditemukan pada anak-anak penyandang ADHD adalah plain whorl, double loop whorl, tanted arch, sedangkan pada anak normal, yang umum ditemukan adalah radial loop, ulnar loop, dan plain whorl lebih tinggi. Perbedaan yang jelas tampak pada tipe pola plain arch yaitu pada anak ADHD 0,5\% dan pada tidak ADHD $0 \%$.

Pola sulur terbentuk sejak embrio berumur 13 sampai 24 minggu perkembangan embrio. Pola-pola sulur pada permukaan telapak tangan dan kaki 
ditentukan oleh poligen, sehingga setiap orang memiliki pola yang berbeda, baik pola, jumlah sulur, kedalaman sulur (Misbach, 2010).

Penyakit keturunan ADHD atau yang dikenal dengan gangguan pusat perhatian yang disertai hiperaktif. Gen yang berperan dalam ADHD yaitu DRD4 pada kromosom 11p (Grady, Moyzis dan Swanson, 2005). Hasil penelitian menunjukan adanya pola yang khas pada anak-anak penyandang ADHD.

Penelitian mengenai dermatoglifi mengenai ADHD belum pernah dilakukan, sehingga penelitian ini merupakan penelitian pendahuluan tentang dermatoglifi pada ADHD. Penelitian terbaru menemukan bahwa lebih kurang 50 penyakit mempunyai hubungan dengan pola-pola dermatoglifi telapak tangan. Penyakit-penyakit tersebut terdiri dari penyakit genetik yang disebabkan oleh satu gen, banyak gen, dan penyakit kromosom (Zhou, Lizhen dan Hu, 2002). Pola-pola tersebut secara umum telah mengalami differensiasi dan evolusi (Lie, et al, 2003).

\section{Frekuensi Pola Sulur Telapak Tangan}

Pola sulur telapak tangan anak ADHD adalah pada thenar (Th), hipothenar (H), interdigital I (I1), interdigital III (I3) dan interdigital IV (I4), tetapi tidak ditemukan hanya pada daerah interdigital II (I2). Pada anak normal ditemukan pola pada hipothenar (H), interdigital (I3), dan Interdigital (I4), tetapi tidak ditemukan pada thenar (th), interdigital 1 (I1) dan interdigital 2 (I2). Frekuensi tertinggi ditemukan pada interdigital 4 (I4).

Penelitian pola sulur pada penyakit keturunan juga memiliki frekuensi yang khas, seperti frekuensi pada anak autis, yaitu tidak ditemukannya pola sulur pada pada daerah $\mathrm{I}_{1}, \mathrm{I}_{2}, \mathrm{I}_{3}$, dan Th pada penderita autisme (Putriani, 2006).

Hal ini mendukung teori bahwa adanya hubungan pola-pola khas telapak tangan dengan beberapa kelainan gen, karena gen penentu ADHD lebih dari satu gen. Gen tersebut mengatur kerja unsur kimiawi saraf (neorochemical) dopamine pada otak. Faktor hereditas juga berupa disfungsi wilayah otak yang berfungsi pelaksana aktivitas dan pengaturan diri (Rief, 2008 dalam Mahabbati, 2013).

\section{SIMPULAN}

Berdasarkan penelitian yang telah dilakukan pada anak-anak penyandang ADHD memiliki tipe plain whorl 34,5\%, lebih banyak dibandingkan dengan anak 
normal (16\%) dan berdasarkan statistik, terdapat perbedaan yang nyata. Rata-rata jumlah sulur ujung jari tangan penyandang ADHD lebih tinggi dibandingkan dengan anak normal $(146,3>136,5)$. Pengamatan pola pada telapak tangan menunjukkan pada interdigital 4 memiliki frekuensi tertinggi (50\%) dan terdapat perbedaan yang tidak nyata antara anak penyadang ADHD dengan anak normal.

\section{DAFTAR PUSTAKA}

Abilasha, S., R. Harisudha, CS. Janak, 2014. Dermatoglyphics: A Predictor To Analyze The Occurrence Of Breast Cancer. International Journal of Medical Research \& Health Sciences. 3(1): 28-31.

Grady, D., Oyzis, M. J. Swansou. 2005. Moleculer Genetics and Attention in ADHD. Clinical Neuroscience Research 5 : 265-272.

Lie, H., H-G Zhang, L. Jin. dan D. Lu. 2003. Evolution, Heredity and GeneLocalization of Intestial Patterns. Journal of Genetic and Molecular Biology. Vol. 14 No. 4, 252-262. December 2003.

Mahabbati, A. 2013. Mengenali Gangguan Attention Defisist Hiperactive Disorder (ADHD) pad Anak. WUNY Majalah Ilmiah Populer. Tahun XV No. 2.

Misbach, Ifa H. 2010. Dahsyatnya Sidik Jari : menguak bakat dan potensi untuk merancang masa depan melalui fingerprint analisis. Jakarta : Visi Media.

Paternotte, A. dan Buitelaar. 2010. ADHD (Attention Deficit Hyperactivity Disorder). Jakarta : Prenada Media Group.

Putriani. E. 2006. Pola Dermatoglifi Ujung Jari dan Telapak Tangan Anak Penderita Autisme di Pusat Terapi Harapan Bunda Air Tawar Padang. Skripsi. FMIPA Jurusan Biologi UNP.

Rafi'ah, Rt., St. Satmoko, Suryadi R, Ramelan W, Yusuf, Yusniar, 1980. Pola TRC dan TTC jari-jari Kelompok Khusus Sarjana dan Kelompok Umum. MajKedoktIndon, $8:$ 198-201

Ramani, P., Abhilash, H. J. Sherlin, Anuja, P. Premkuman, Chandra sekar, Senamilselvi, Janaki. 2011. Conventional Dermatoglyphics Revived Concept: A Review. International Journal of Pharma and Bio Science. Vol12/Issue 3/Jul-Sept 2011.

Sudarmi. 2004. Dermatoglifi Ujung Jari dan Telapak Tangan Penderita Hipertensi. Skripsi. Padang : FMIPA Jurusan Biologi UNP.

Sufitni. 2007. Pola Sidik Jari Pada Kelompok Retardasi Mental dan Kelompok Normal. Majalah Kedokteran Nusantara. 40 (3) : 180-191.

Zhou, Y., Y. Z. Lizhen dan W. Hu 2002. Application and development of palm print research. Technology and Health Care. 10 : 383-390. 